\section{Clinical applications of Doppler ultrasonography for thyroid disease: consensus statement by the Korean Society of Thyroid Radiology}

Jin Chung ${ }^{1 *}$, Yoo Jin Lee ${ }^{2^{*}}$, Young Jun Choi ${ }^{3}$, Eun Ju Ha ${ }^{4}$, Chong Hyun Suh ${ }^{3}$, Miyoung $\mathrm{Choi}^{5}$, Jung Hwan Baek ${ }^{3}$, Dong Gyu $\mathrm{Na}^{6,7}$, Korean Society of Thyroid Radiology (KSThR), Korean Society of Radiology

1 Department of Radiology, Ewha Womans University College of Medicine, Seoul; ' 2 Department of Radiology, Busan Paik Hospital, Inje University College of Medicine, Busan; ${ }^{3}$ Department of Radiology and Research Institute of Radiology, Asan Medical Center, University of Ulsan College of Medicine, Seoul; ${ }^{4}$ Department of Radiology, Ajou University School of Medicine, Suwon; ${ }^{5}$ Division for Healthcare Technology Assessment Research, National Evidencebased Healthcare Collaborating Agency, Seoul; ${ }^{6}$ Department of Radiology, GangNeung Asan Hospital, Gangneung; ${ }^{7}$ Human Medical Imaging and Intervention Center, Seoul, Korea

Doppler ultrasonography (US) is widely used for the differential diagnosis of thyroid nodules, metastatic cervical lymph nodes in patients with thyroid cancer, and diffuse parenchymal disease, as well as for guidance in various US-guided procedures, including biopsy and ablation. However, controversies remain regarding the appropriate use and interpretation of Doppler US. Therefore, the Korean Society of Thyroid Radiology organized a taskforce to develop a consensus statement on the clinical use of Doppler US for thyroid disease. The review and recommendations in this article are based on a comprehensive analysis of the current literature and the consensus of experts.

Keywords: Thyroid; Doppler ultrasound

\section{Introduction}

Doppler ultrasound (US) is an imaging technique that exploits the shift in the frequency of US waves when they are reflected by moving blood (the Doppler effect) [1]. Doppler US can provide information on perithyroidal vessels and the vascularity of thyroid lesions and is widely used in daily practice for the evaluation of thyroid disease alongside gray-scale US. There are several types of Doppler US techniques, including spectral Doppler US (SDUS), color Doppler US (CDUS), power Doppler US (PDUS), and superb microvascular imaging (SMI). Many studies have used these techniques and

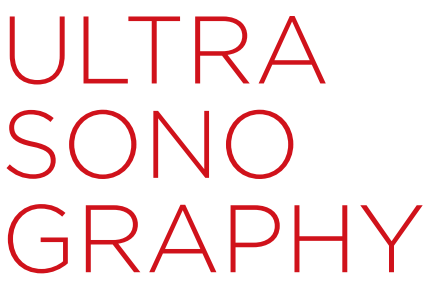

REVIEW ARTICLE

https://doi.org/10.14366/usg.20072 pISSN: 2288-5919 • elSSN: 2288-5943 Ultrasonography 2020;39:315-330

Received: May 22, 2020

Revised: August 24, 2020

Accepted: August 25, 2020

Correspondence to:

Young Jun Choi, MD, PhD, Department of Radiology and Research Institute of Radiology, Asan Medical Center, University of Ulsan College of Medicine, 88 Olympic-ro 43-gil, Songpa-gu, Seoul 05505, Korea

Tel. +82-2-3010-4400

Fax. +82-2-476-0090

E-mail: jehee23@gmail.com

* These authors contributed equally to this work.

This is an Open Access article distributed under the terms of the Creative Commons Attribution NonCommercial License (http://creativecommons.org/ licenses/by-nc/4.0/) which permits unrestricted noncommercial use, distribution, and reproduction in any medium, provided the original work is properly cited.

Copyright @ 2020 Korean Society of Ultrasound in Medicine (KSUM)

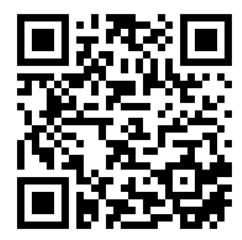

How to cite this article:

Chung J, Lee YJ, Choi YJ, Ha EJ, Suh CH, Choi $\mathrm{M}$, et al. Clinical applications of Doppler ultrasonography for thyroid disease: consensus statement by the Korean Society of Thyroid Radiology. Ultrasonography. 2020 Oct:39(4):315-330. 
reported different results regarding focal thyroid nodules and diffuse parenchymal disease [2-11]. Doppler US is also widely used for USguided procedures, such as biopsy and ablation of thyroid nodules $[3-7,12,13]$. With the increasing use of these procedures, there is a need for a consensus statement on the clinical applications of Doppler US for thyroid disease.

In March 2019, the Korean Society of Thyroid Radiology organized a taskforce to develop a consensus statement on the clinical applications of Doppler US for thyroid disease. The recommendations include the basic principles and techniques of Doppler US and their clinical applications for thyroid nodules, metastatic cervical lymph nodes in patients with thyroid cancer, diffuse parenchymal disease, and US-guided procedures. A PubMed/MEDLINE search using the keywords "thyroid," "Doppler," "vascular," and "ultrasound" was performed to retrieve publications from January 2000 to April 2019. The draft consensus statement for the clinical application of Doppler US for thyroid disease was posted on the official website (https://www.thyroidimaging.kr/) and was reviewed by members of the Korean Society of Thyroid Radiology. The goal of these recommendations is to summarize the best scientific evidence available and to provide a consensus expert opinion on the use of Doppler US for thyroid disease.

\section{Basic Principles and Techniques of Doppler US}

Doppler US is based on the Doppler effect and utilizes the change in the frequency of a sound wave resulting from motion. In Doppler US, the Doppler effect allows one to detect the movement of red blood cells in the blood vessels. Thus, Doppler US provides information on blood flow, which is related to the vascularization of anatomical structures. Several Doppler US techniques have been used to evaluate thyroid gland lesions, including SDUS, CDUS, PDUS, and SMI.

SDUS displays a spectrum of flow velocities represented graphically on the $\mathrm{Y}$-axis against time on the $\mathrm{X}$-axis. Thus, the spectral mode allows us to measure different blood flow parameters. CDUS involves a combination of the Doppler effect and real-time US imaging. In CDUS, the information from the Doppler technique is integrated with the B-mode (i.e., gray-scale) image to form a color signal with the colors indicating the direction of flow; red usually indicates flow toward the transducer and blue indicates flow away from the transducer. PDUS displays the power of the Doppler shift in small volumes within the field of view, while CDUS displays the mean Doppler shift. Therefore, PDUS potentially offers increased sensitivity for detecting low-velocity flow in small vessels [14]. SMI deals with the issue that Doppler signals are derived not only from the blood flow, but also from tissue motion (clutter); as a result, the clutter signals overlap the low-speed flow components. Conventional Doppler techniques apply a single-dimensional wall filter to remove clutter, resulting in loss of the slow component. In contrast, SMI uses a multidimensional filter to separate flow signals from clutter, thus removing only the clutter while preserving the slow-flow signals [12]. Additionally, contrast-enhanced US (CEUS) refers to the application of US contrast agents in medical US. CEUS can provide anatomic information with gray-scale US and physiologic information through the SDUS, CDUS, and PDUS techniques, making it indispensable in the assessment of vascular pathology [15-21]. The presence of a microbubble US contrast agent in the vasculature enhances the backscattering of US waves, resulting in a marked amplification of flow signals and providing information on the microvasculature $[12,21,22]$.

\section{Clinical Applications of Doppler US}

\section{Diagnosis of Focal Thyroid Nodules \\ Differential diagnosis of benign and malignant thyroid nodules}

\section{Color Doppler US}

The vascularity patterns of thyroid nodules on CDUS can be categorized into four types: type 1, absence of nodule vascularity; type 2, perinodular vascularity only (presence of circumferential vascularity at the margin of a nodule); type 3, mild intranodular vascularity with or without perinodular vascularity (vascularity $<50 \%$ ); and type 4, marked intranodular vascularity with or without perinodular vascularity (vascularity $>50 \%$ ) (Fig. 1) [8].

CDUS can be clinically applied for the differential diagnosis of benign and malignant thyroid nodules, as it has high sensitivity and specificity [23-28]. Papini et al. [24] prospectively evaluated the predictive value of CDUS in 494 patients and reported that intranodular vascular spots (odds ratio, 14.23) were an independent risk factor of malignancy. In another prospective study including 90 patients, Ebeed et al. [29] reported similar results, observing CDUS patterns of obvious intranodular blood flow with absent or slight perinodular blood flow (type 3) in malignant thyroid nodules, with sensitivity, specificity, and accuracy for malignancy of $79.2 \%, 95.6 \%$, and $88.7 \%$, respectively. In two retrospective studies, extensive internal flow was associated with malignant thyroid nodules $[25,30]$; one study reported that the sensitivity, specificity, and accuracy of CDUS for the detection of malignant thyroid nodules were $93.6 \%$, $86.7 \%$, and $90.7 \%$, respectively [25]. However, in a prospective study by Hong et al. [27] that included 243 patients, marked intranodular vascularity, defined as greater flow in the central part of the nodule than in the periphery, had a disappointingly low diagnostic performance (sensitivity of $31 \%$ and specificity of $81 \%$ ). They also demonstrated that marked intranodular vascularity was 
more commonly observed in large thyroid nodules than in small malignant or benign thyroid nodules ( $\mathrm{P}=0.01$ for malignant nodules and $\mathrm{P}=0.001$ for benign nodules) [27]. In a recently published metaanalysis of 20 studies, CDUS showed a pooled sensitivity of $74 \%$ (95\% confidence interval $[\mathrm{Cl}], 62 \%-83 \%$ ) and a pooled specificity of $70 \%(95 \% \mathrm{Cl}, 56 \%-81 \%)$ for the diagnosis of malignant nodules and an area under the curve (AUC) of $0.78(95 \% \mathrm{Cl}, 0.74-$ 0.81 ) on summary receiver operating characteristic (ROC) curve analysis [23]. In summary, CDUS shows acceptable diagnostic performance and may be useful for predicting malignant thyroid nodules. Marked intranodular vascularity on CDUS is a significant predictor of malignancy in thyroid nodules [23-30].

\section{Power Doppler US}

PDUS performed with a high-frequency transducer allows identification of low-velocity blood flow in superficial organs, such as the thyroid gland [31-34]. PDUS may be more sensitive than CDUS in detecting the slow flow of small vessels (Fig. 2) $[31,34]$. Several previous studies have suggested that PDUS is highly sensitive and specific in differentiating between benign and malignant thyroid nodules [31-33]. Chammas et al. [31] evaluated the predictive value of PDUS in 177 thyroid nodules from 174 patients and reported



A

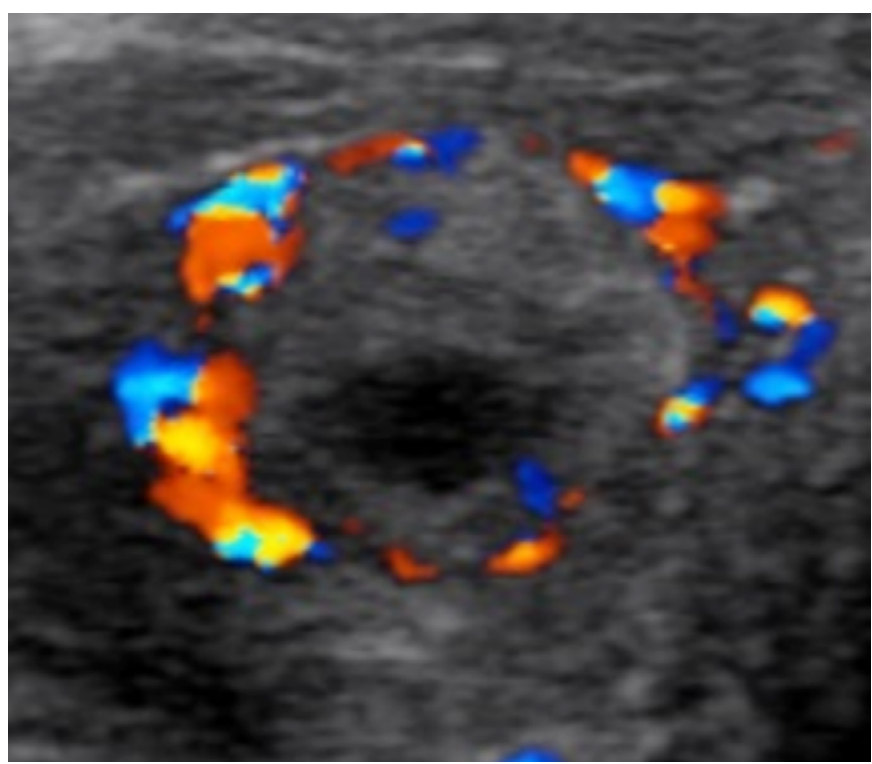

B

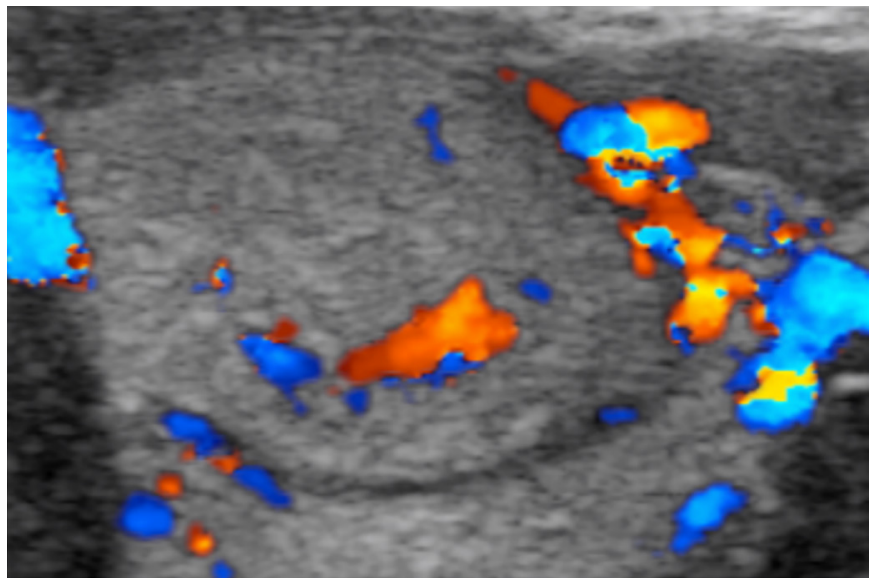

C

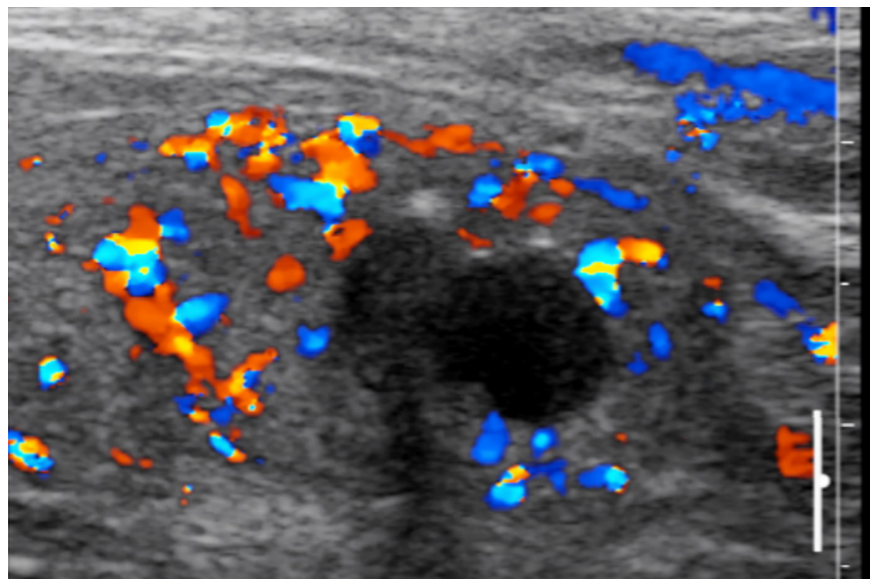

D

Fig. 1. Vascular patterns of thyroid nodules on color Doppler ultrasonography.

The patterns are categorized into four types: type 1, absence of thyroid nodule vascularity (A); type 2, perinodular vascularity only (presence of circumferential vascularity at the margin of a thyroid nodule) (B); type 3, mild intranodular vascularity with or without perinodular vascularity (vascularity <50\%) (C); type 4, marked intranodular vascularity with or without perinodular vascularity (vascularity $>50 \%)$ (D). 


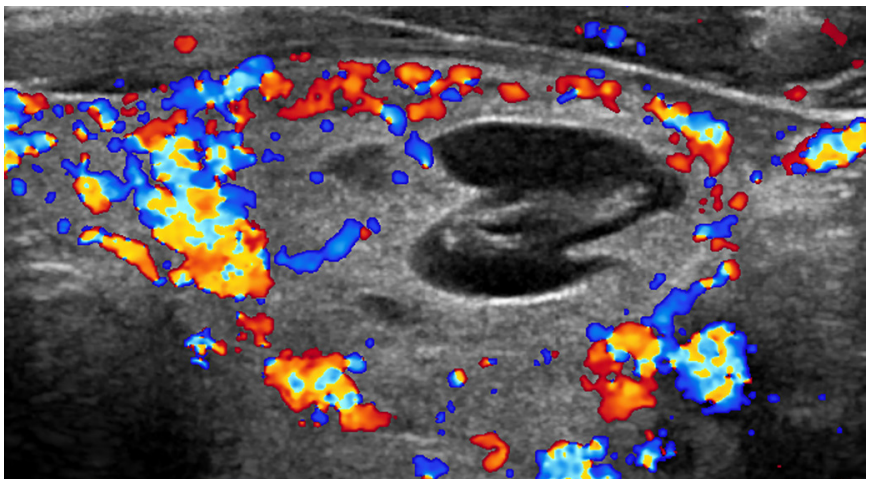

A

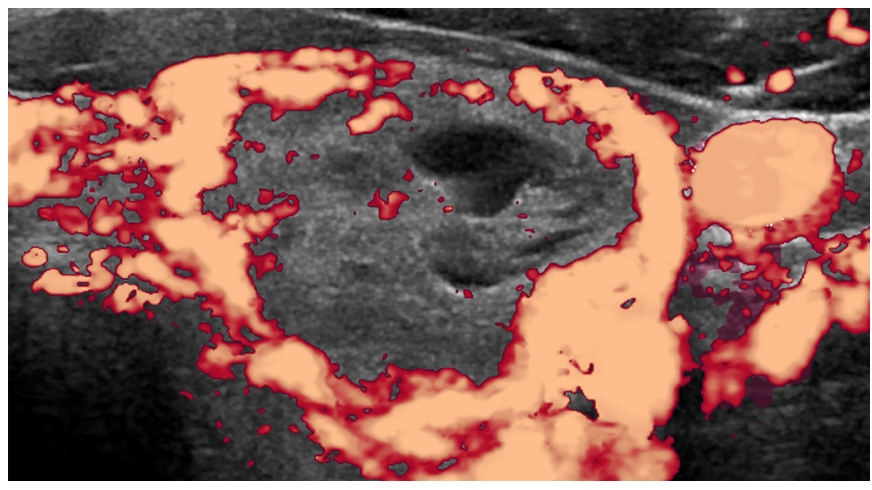

B

Fig. 2. A 49-year-old woman with benign follicular adenoma.

A. Transverse color Doppler sonography shows increased perinodular vascularity. B. Transverse power Doppler sonography shows more increased perinodular vascularity than the color Doppler sonography.

that nodules with central or mainly central vascularization patterns (type 4 or 5 ) were an independent risk factor for malignancy (odds ratio, 219). Several previous studies have demonstrated that the risk of thyroid malignancy increases as marked intranodular blood flow becomes more predominant [31-33]. However, these results are inconsistent with those of other studies that showed an absence of blood flow signal in papillary carcinomas [35-37]. A retrospective study by Moon et al. [37] including 1,083 thyroid nodules evaluated three patterns of vascularity (none, peripheral, and intranodular) on PDUS. The authors reported that intranodular vascularity was frequently seen in benign thyroid nodules, while an absence of vascularity was more frequent in malignant thyroid nodules $(P<0.001)$ and that vascularity itself or a combination of vascularity and gray-scale US features was not as useful as suspicious grayscale US features alone for predicting thyroid malignancy [37]. The use of the flow pattern on PDUS to predict thyroid malignancies is controversial.

\section{Spectral Doppler US}

SDUS displays a spectrum of flow velocities; therefore, it can provide information on multiple blood flow parameters. The peak systolic velocity (PSV), mean systolic velocity (MSV), and end diastolic velocity (EDV) are measured, while the resistive index (RI) and pulsatile index (PI) are calculated using the following formulas $[28,38]$ :

$$
\begin{aligned}
& \mathrm{RI}=(\mathrm{PSV}-\mathrm{EDV}) / \mathrm{PSV} \\
& \mathrm{Pl}=(\mathrm{PSV}-\mathrm{EDV}) / \mathrm{MSV}
\end{aligned}
$$

Several studies have reported that when combined with gray-scale US, SDUS can improve the diagnosis of thyroid malignancy $[28,38]$. In a prospective study by Palaniappan et al. [28] evaluating the predictive value of SDUS in 214 thyroid nodules of 194 patients, the mean $\mathrm{RI}$ and PI of malignant thyroid nodules was 0.73 and 1.3, respectively, which were significantly higher than those of benign nodules, and the sensitivity, specificity, and accuracy of SDUS for the diagnosis of malignant thyroid nodules were $76.8 \%, 81.7 \%$, and $80.6 \%$, respectively. An additional cross-sectional study confirmed these results and reported a significant association between $\mathrm{PI}$ and malignancy, using a PI cutoff of $\geq 0.945$ ( $P=0.007)$ for determining malignancy [38]. Chammas et al. [31] reported similar results-an $\mathrm{RI}>0.77$ was an independent risk factor for malignancy of a nodule (odds ratio, 4.1) and a combination of PDUS and RI had a diagnostic sensitivity and specificity of $92.3 \%$ and $88 \%$, respectively, for the detection of malignant thyroid nodules. Further, another study by Algin et al. [39] showed that the RI and PI values were higher in malignant thyroid nodules than in benign thyroid nodules $(P<0.05)$ [39]. In summary, the RI and PI values of SDUS are significantly higher in malignant nodules than in benign nodules, and SDUS has acceptable diagnostic performance for the prediction of malignant thyroid nodules.

\section{Contrast-enhanced US}

CEUS is widely used to evaluate microvascularization and tumor angiogenesis, which are helpful for the differential diagnosis of malignancy and benignity $[40,41]$. CEUS was first used to evaluate focal liver lesions when B-mode and Doppler US yielded equivocal results [42]. With improvements in US equipment and the introduction of second-generation contrast agents (e.g., SonoVue [Bracco Imaging, Milan, Italy]) for the characterization of malignant thyroid nodules, the accuracy of CEUS for predicting thyroid malignancy has improved and its use has increased $[43,44]$. The following is the general process of CEUS for thyroid nodules. The focus zone is always placed at the bottom level of the nodule, 
and CEUS is performed using a low mechanical index $(<0.10)$. The contrast agent is injected intravenously as a bolus, followed by a saline flush. The timer on the US machine is started during the CEUS process, and the images are obtained during the next 2-3 minutes [44].

The degree of enhancement of thyroid nodules on CEUS is divided into three patterns in reference to the surrounding parenchyma: hyperenhancement, isoenhancement, and hypoenhancement [44]. Hypoenhancement is a major CEUS pattern characteristic of malignant thyroid nodules [44-47]. When hypoenhancement was used as the diagnostic criterion for malignant thyroid nodules, the sensitivity, specificity, and accuracy of CEUS were $82.1 \%-89.8 \%$, $80 \%-91.8 \%$, and $84 \%-91 \%$, respectively [45-47]. The main reason for hypoenhancement in malignant thyroid nodules is the lack of blood supply in a nodule because of necrosis and embolus formation within the tumor [44]. Another important CEUS pattern characteristic of malignant thyroid nodules is heterogeneous enhancement $[44-46,48,49]$. When heterogeneous enhancement was used as the diagnostic criterion for thyroid malignancy, the sensitivity, specificity, and accuracy of CEUS were $88 \%-90.4 \%$, $80 \%-92.5 \%$, and $85 \%-91 \%$, respectively $[45,46,48,49]$. The blood vessels of malignant nodules are typically aberrant and tortuous, whereas those of benign nodules are usually regular [48]. Furthermore, most malignant thyroid nodules include areas of calcification, fibrosis, and/or necrosis, which are related to heterogeneous enhancement [44]. In addition to qualitative assessments of thyroid nodules, quantitative assessments are important for predicting malignancy with CEUS. CEUS with time-intensity curve analysis is helpful in diagnosing malignant thyroid nodules [44,50,51]. Chen et al. [51] evaluated the CEUS characteristics of 130 papillary thyroid microcarcinomas in 106 patients and reported that the peak enhancement intensity was lower than that of normal thyroid parenchyma and that contrast washed out faster from papillary thyroid microcarcinomas than from normal thyroid parenchyma. Furthermore, Nemec et al. [52] found that relative enhancement during the washout curve was lower in malignant thyroid nodules than in benign nodules, with an optimal cutoff value of 2.35 for predicting malignancy. Using this cutoff value, the diagnostic performance of CEUS had $76.9 \%$ sensitivity, $69.7 \%$ specificity, and $69.6 \%$ accuracy [52].

On CEUS, hypoenhancement and heterogeneous enhancement are major findings of malignant thyroid nodules [44-49]. CEUS with time-intensity curve analysis is also helpful in distinguishing benign from malignant thyroid nodules [50-52].

Superb microvascular imaging

SMI analyzes clutter motion and uses a new algorithm to identify and remove tissue motion, allowing the imaging of microvascular blood flow [53]. SMI depicts perinodular and intranodular thyroid microvascular flow in higher detail than conventional CDUS or PDUS $[54,55]$. Zhu et al. [55] prospectively compared SMI, gray-scale US, and CDUS in distinguishing between benignity and malignancy in 76 thyroid nodules and reported that SMI was significantly more accurate for identifying malignant thyroid nodules (79.3\%) than CDUS (55.2\%; $P<0.001)$. Gray-scale US with SMI resulted in the greatest diagnostic sensitivity, specificity, and accuracy $(86.2 \%$, $85.1 \%$, and $85.5 \%$, respectively), and the AUC value for ROC analysis of gray-scale US with SMI $(0.911$ [ $95 \% \mathrm{Cl}, 0.849-0.973])$ was significantly better than those of gray-scale US with CDUS or gray-scale US alone [55]. Vascularity on SMI is classified into three types: none, peripheral, and mixed and intranodular [56]. Kong et al. [56] evaluated the vascularity of 113 thyroid nodules and showed that for the diagnosis of thyroid malignancies, intranodular vascularity on SMI had a $91.2 \%$ specificity and $75.9 \%$ sensitivity, superior to the $82.3 \%$ specificity and $41.8 \%$ sensitivity of PDUS $(\mathrm{P}<0.01)$. The authors demonstrated that a taller-than-wide shape, microcalcifications, and intranodular vascularity on SMI were independent risk factors for thyroid malignancy [56]. An alternative classification of the vascularity on SMI used the number of vessels inside the thyroid nodule, with a score of 1 for a maximum of two blood vessels on SMI and a score of 2 for three or more vessels on SMI [54]. Zhu et al. [55] showed that a score of 2 was found in $40.4 \%$ benign nodules and $82.1 \%$ malignant nodules (sensitivity, $81.7 \%$; specificity, $60.5 \%$ ) and that an SMI score of 2 was an independent risk factor for thyroid malignancy $(P<0.001)$. In summary, SMI is an emerging additional modality to conventional US. SMI is more accurate than CDUS or PDUS for the assessment of malignant thyroid nodules, and SMI findings of a large number of vessels and intranodular flow are associated with malignancy in thyroid nodules [54-56].

\section{Diagnosis of follicular neoplasms}

Follicular thyroid carcinoma accounts for $10 \%-20 \%$ of all thyroid malignancies. Most cases of follicular thyroid carcinoma require surgical biopsy or excision to determine the diagnosis [57]; however, $>80 \%$ of all thyroid follicular neoplasms are benign [58]. CDUS is useful for predicting malignant thyroid follicular neoplasms $[2,59]$. The most hypervascular thyroid nodule types are adenoma/ adenomatoid nodules, the encapsulated subtype of the follicular variant of papillary thyroid carcinoma, and follicular carcinoma [60]. A meta-analysis of CDUS for predicting malignant thyroid follicular neoplasms [2] showed an overall sensitivity of $85 \%$ and specificity of $86 \%$ and found that a predominant internal flow seen on CDUS was associated with malignant thyroid follicular neoplasms (Fig. 


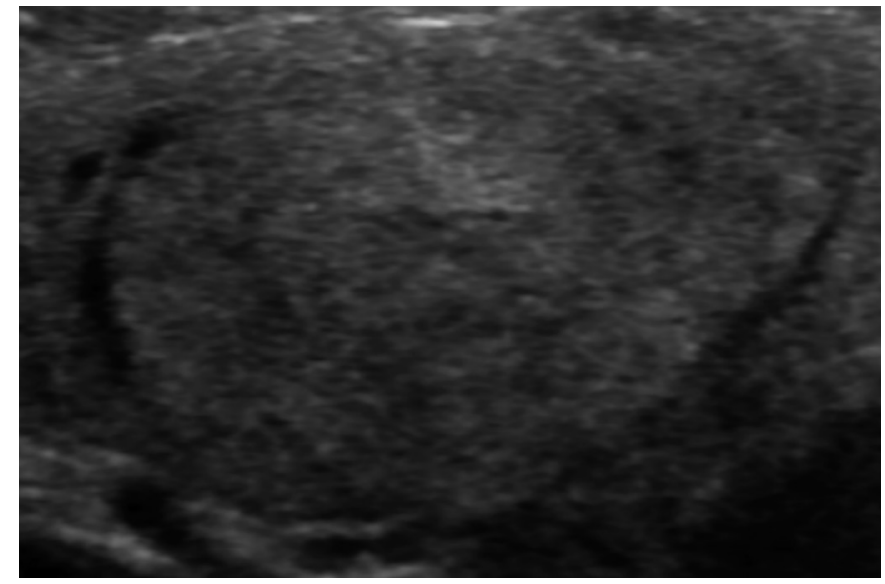

A

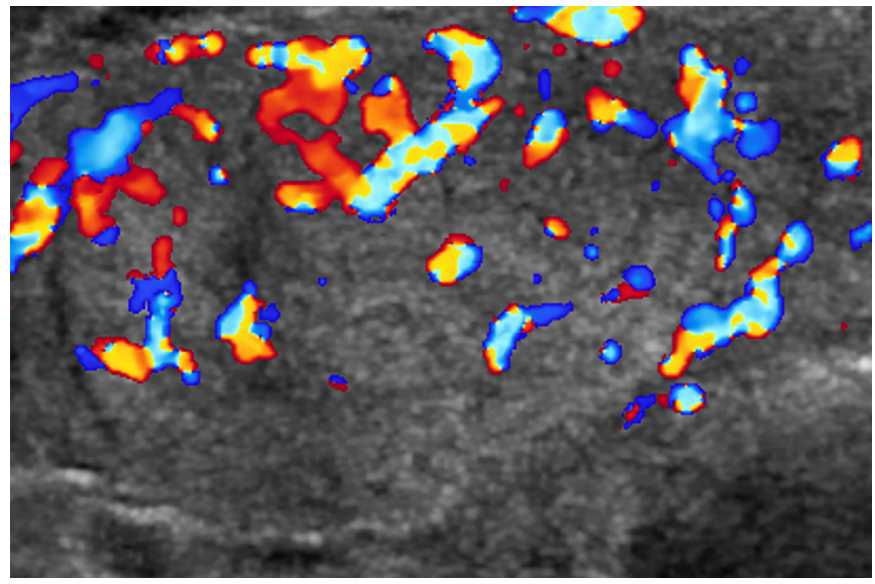

B

Fig. 3. A 53-year-old woman with minimally invasive follicular carcinoma.

A. Transverse gray-scale sonography shows an isoechoic mass in the right thyroid. B. Predominant internal flow is seen in the thyroid nodule on a transverse color Doppler sonography.

3). Fukunari et al. [60] used a CDUS and SDUS diagnostic grading system for the differential diagnosis of thyroid follicular lesions as follows: grade 1, benign follicular lesion (no color flow inside the nodule); grade 2, benign peripheral type (color flow only in the peripheral area, $\mathrm{Pl}<1.0$ ); grade 3, suspected follicular carcinoma (penetrating color flow, moderate vascularity); and grade 4, follicular carcinoma (high-velocity penetrating color flow, $\mathrm{Pl}=1.0$ ). On the assumption that grade 1 and 2 lesions are benign and grade 3 and 4 lesions are malignant, the sensitivity, specificity, and accuracy for predicting malignant thyroid follicular neoplasms were $88.9 \%$, $74.2 \%$, and $81.0 \%$, respectively [2]. Additionally, Miyakawa et al. evaluated the vascular pattern of PDUS and the parameters of SDUS and reported that the majority (84\%) of follicular adenomas showed only a peripheral rim of color flow on PDUS and that the $\mathrm{PI}$ and RI values on SDUS were significantly higher in patients with follicular carcinoma than in those with follicular adenoma $(P<0.005$ and $P<0.001$, respectively). Follicular carcinoma can be diagnosed with a cutoff values of $\mathrm{PI}>1.35$ and $\mathrm{RI}>0.78$, respectively, with AUC values of 0.898 for $\mathrm{Pl}$ and 0.876 for RI on ROC analysis [61]. In summary, Doppler US may be a useful additional method for differentiating benign from malignant thyroid follicular neoplasms; predominant internal blood flow is seen in the latter $[2,59,60]$. SDUS parameters are also helpful for the diagnosis of malignant thyroid follicular neoplasm $[60,61]$, with PI and RI being higher in malignant thyroid follicular neoplasms than in benign thyroid follicular neoplasms $[60,61]$. However, predominant internal blood flow can also be seen in benign thyroid nodules. Using predominant internal blood flow, the overall sensitivity for predicting thyroid malignancy was very high (96\%), although the specificity was very low (14\%), with positive and negative predictive values of
$15 \%$ and $96 \%$, respectively [2]. A systematic review and metaanalysis reported that CDUS had an overall sensitivity of $85 \%$ and a specificity of $86 \%$ for thyroid follicular neoplasms, with positive and negative predictive values of $51 \%$ and $97 \%$, respectively [2].

\section{Diagnosis of metastatic cervical lymph nodes in patients with thyroid cancer}

Diagnosing metastatic lymph nodes in patients with thyroid cancer is important when planning surgery. Gray-scale US has been established as a primary imaging modality. Moreover, the combination of Doppler US and gray-scale US can increase the diagnostic accuracy. Hilar or central vascularity of the lymph node is a typical finding of a benign lymph node. In contrast, peripheral or diffuse vascularity is a US characteristic of lymph nodes with metastasis from thyroid cancer, and the absence of central hilar vascularity is a US criterion for an indeterminate lymph node $[8,62]$. Leboulleux et al. [63] prospectively evaluated the diagnostic accuracy of US for lymph node metastasis in 56 lymph nodes from 19 patients with differentiated thyroid cancer. They reported that the pattern of vascularity (peripheral vascularity in PDUS) had the best sensitivity and specificity ( $86 \%$ and $82 \%$, respectively) among the US findings, making the use of Doppler US essential in the followup of differentiated thyroid cancer [63]. A previous study of CEUS showed similar results, in which heterogeneous, centripetal, and hybrid (mixture of centripetal and centrifugal) enhancement were significantly related to lymph node metastasis and CEUS showed a higher sensitivity ( $82 \%$ vs. $92 \%$ ) and accuracy (79\% vs. $72 \%$ ) than conventional US [64]. In another study using SDUS, 76\% of metastatic lymph nodes demonstrated peripheral vascularity and $85 \%$ of metastatic lymph nodes in patients with papillary 
thyroid carcinoma had maximum RI and PI values of 0.8 and 1.6, respectively [65]. Sometimes, parathyroid lesions can be mistaken for metastatic lymph nodes [66], but parathyroid adenoma shows a characteristic polar vessel sign in addition to its characteristic location [67]. In summary, central hilar vascularity is a typical finding of benign lymph nodes, but peripheral vascularity on Doppler US is an important finding with acceptable diagnostic performance for identifying metastatic lymph nodes in patients with thyroid cancer.

\section{Summary, consensus, and limitations}

Marked internal vascularity on CDUS and SMI may be a major finding of malignant thyroid nodules [23-30,54-56]. The emerging modality of SMI can reveal more vascular details than CDUS or PDUS [33-35]. However, the populations in previous studies had a wide range of prevalence of papillary thyroid carcinomas (63.3\%$90.6 \%$ ) $[16,44-46]$. The parameters of SDUS, including PI and RI, may be important in differentiating benign from malignant thyroid nodules $[28,29,31,38,39]$. Hypoenhancement and heterogeneous enhancement on CEUS may be major features of malignant thyroid nodules [44-49]. Peripheral vascularity on Doppler US is a major finding for diagnosing metastatic cervical lymph nodes in patients with thyroid cancer $[8,62]$.

Although many studies have reported that Doppler US is useful for the differentiation of thyroid nodules, few studies have evaluated the added value of Doppler US over gray-scale US for the differentiation of thyroid nodules [55]. Future studies on the added value of Doppler US is necessary for risk stratification and biopsy decision-making. Additionally, there are regional disproportions in studies and many studies in the literature had low-quality designs (small numbers of patients and retrospective designs). Further studies are required on the use of Doppler US for the prediction of malignant thyroid nodules.

\section{Diagnosis of Diffuse Parenchymal Disease of the Thyroid Gland}

Although clinical and laboratory findings play a more substantial role in the diagnosis and treatment of diffuse thyroid disease (DTD), thyroid US makes an important contribution to the diagnosis of DTD [9-11]. The known gray-scale US features of DTD include increased or decreased parenchymal echogenicity, coarse echotexture, increased or decreased anteroposterior (AP) diameter of the thyroid, and the presence of marginal nodularity. Specific US findings for Graves disease (GD) and Hashimoto thyroiditis (HT) are thyroid inferno and micronodulation, respectively [68-72]. DTD can increase or decrease the vascularity of the thyroid gland, although differences in the extent of fibrosis and inflammation can also affect any measured values of vascularity [73-76].
Doppler US of the thyroid gland is helpful for the early detection of incidental asymptomatic DTD [69,77-79] and the differential diagnosis of GD with destructive thyroiditis in thyrotoxicosis [73-76,80-86]. It can also provide valuable information on the functional status of the thyroid and can be used to evaluate disease remission, recurrence, and response to treatment $[68,73,81,84,87]$.

\section{Differentiation of asymptomatic DTD from the normal thyroid gland}

Thyroid US can be helpful in differentiating asymptomatic DTD from normal thyroid parenchyma $[69,77-79]$. A recent multicenter study found significant differences in US features of the thyroid gland between patients with normal thyroid parenchyma $(n=139)$ and those with asymptomatic DTD ( $n=64 ; H T$, non- $H T$, and diffuse hyperplasia; $P<0.001$ ); these differences included parenchymal echogenicity, parenchymal echotexture, AP diameter of the thyroid gland, glandular margin, and parenchymal vascularity. Several US features, including decreased or increased parenchymal echogenicity, coarse parenchymal echotexture, increased AP diameter $(>2 \mathrm{~cm})$, lobulated glandular margin, and increased parenchymal vascularity, were independent predictors of DTD (Fig. 4). The diagnostic ability of US was highest when a criterion of one or more of these abnormal US features were chosen, with a sensitivity of $85.9 \%$ and specificity of $63.3 \%$ [77]. Similarly, several investigators have demonstrated that three or more abnormal US features indicated a high likelihood of incidental DTD, with a sensitivity of $87.7 \%$ and specificity of 92.1\% [69] and that one abnormal US feature showed the highest diagnostic accuracy, with a sensitivity of $80.5 \%$ and specificity of $85.7 \%[78]$.

Gray-scale US can provide the volume of the thyroid gland and indicate features of DTD. The thyroid gland volume can be obtained from maximum measures in the longitudinal $(L), A P$, and transverse $(T)$ axes of both lobes and the isthmus using the ellipse correction coefficient (thyroid volume $=L \times A P \times T \times \pi / 6$ ) [84]. In addition, unusual focal lesions found in patients with DTD need to be evaluated according to their features on B-mode and Doppler US and an investigation by fine-needle aspiration (FNA) biopsy may be indicated because papillary thyroid carcinoma and primary thyroid lymphoma are more likely in patients with HT than in the general population [88].

\section{Differential diagnosis of GD from destructive thyroiditis in thyrotoxicosis}

Doppler US is useful for the differential diagnosis of GD from destructive thyroiditis, which causes thyrotoxicosis in its early stage. Destructive thyroiditis includes $\mathrm{HT}$, subacute granulomatous thyroiditis, postpartum thyroiditis, and painless (silent) thyroiditis 


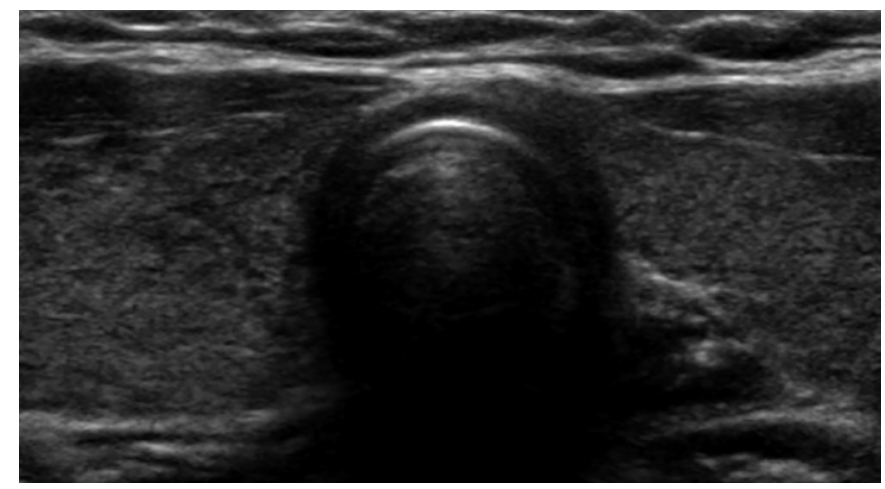

A

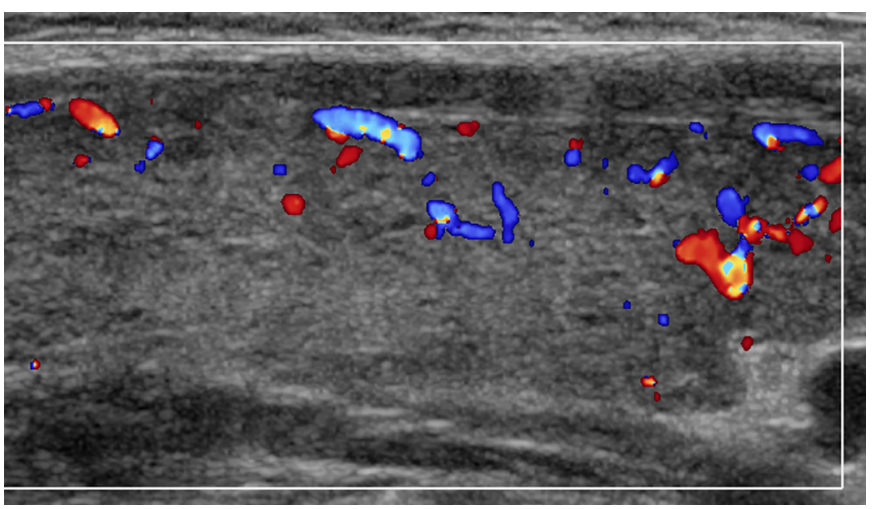

C

[73-76]. Before treatment or effective therapy, GD shows a diffuse increase in vascularization of the parenchyma, referred to as thyroid inferno, a term first used by Ralls et al. in 1988 [68]. Thyroid hypervascularization can also occur in $\mathrm{HT}$, but to a lesser degree (Fig. 5) $[76,85,86]$. The vascularity of the thyroid parenchyma can be determined using a visual scale according to the classification created by Schulz et al. [89]: pattern 0, blood flow limited to the peripheral thyroid arteries while parenchymal flow is absent; pattern I, presence of mildly increased parenchymal flow; pattern II, clearly increased color flow with a diffuse homogenous distribution; and pattern III, markedly increased color flow with a homogenous distribution.

Quantitative measurement of thyroid arterial blood flow is a useful parameter for the differential diagnosis of thyrotoxicosis. PSV measurements of the thyroid artery have become accurate and reliable with excellent reproducibility $[75,83,86]$. PSV measurement of thyroid arteries is performed using a 1- to 3-mm sample volume adjustment in the vessel center. The Doppler angle should be kept at or below $60^{\circ}$ and the correction angle should be adjusted parallel to the direction of flow $[75,83,86]$. There is generally no substantial difference between PSV measurements made on the superior or inferior thyroid arteries or on the inferior thyroidal arteries of either



B

Fig. 4. A 50-year-old woman with Hashimoto thyroiditis diagnosed as diffuse thyroid disease on sonography.

Transverse (A) and longitudinal (B) gray-scale sonography show decreased echogenicity, coarse echotexture, a normal anteroposterior diameter of the thyroid gland, and lobulated margins. Longitudinal color Doppler sonography (C) shows increased parenchymal vascularity of the thyroid.

side $[76,80-82,86]$. The cutoff value for differentiating GD from thyroiditis is $40-50 \mathrm{~cm} / \mathrm{sec}[76,82,83,86]$. In a study by Donkol et al. [76] on the differential diagnosis of GD and HT, Doppler US demonstrated a sensitivity of $88.9 \%$, a specificity of $87.5 \%$, a positive predictive value of $94.1 \%$, a negative predictive value of $77.8 \%$, and a diagnostic accuracy of $88.5 \%$ compared the reference standard of ${ }^{99 \mathrm{~m}} \mathrm{Tc}$ scintigraphy. Similarly, in a study by Hari Kumar et al. [85], Doppler US had a sensitivity of $96 \%$ and specificity of $95 \%$ for the differential diagnosis of thyrotoxicosis in reference to ${ }^{99 m}$ Tc scintigraphy. Other methods of estimating thyroid blood flow, such as thyroid blood flow area, vascularization index, and highresolution power Doppler, have also been used to provide better differentiation $[68,84,90]$.

\section{Evaluation of disease remission, recurrence, and response to treatment in DTD}

In patients with $G D$, thyroid gland vascularization correlates with the underlying functional status, and this vascularization decreases when the disease is under control, but it can increase in cases of recurrence. Many authors have reported that a decrease in vascularity occurs in parallel with biochemical remission and disease control in GD and suggested that thyroid Doppler US has the 


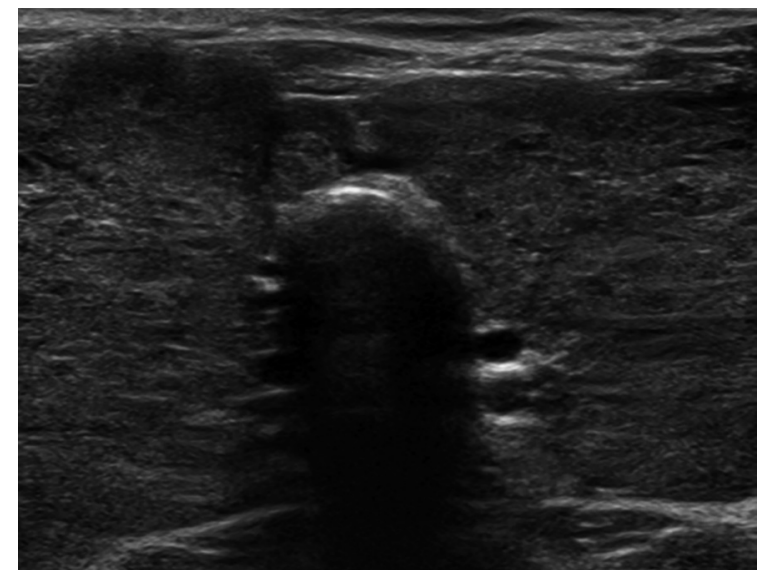

A

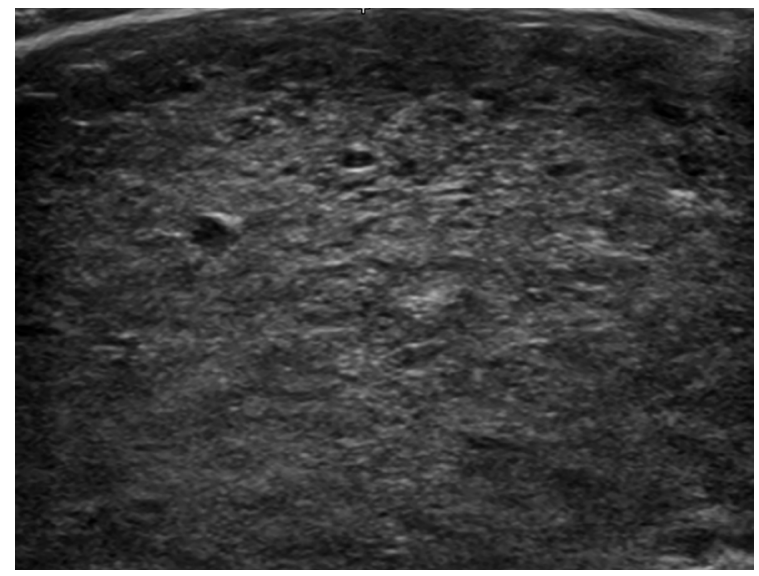

B



C



D

Fig. 5. A 31-year-old man with Graves disease diagnosed as diffuse thyroid disease on sonography.

Transverse (A) and longitudinal (B) gray-scale sonography show decreased echogenicity, coarse echotexture, an increased anteroposterior diameter of the thyroid gland, and smooth margins. A qualitative visual assessment of thyroid parenchymal vascularity on longitudinal color Doppler sonography (C, D) revealed thyroid inferno (C), while quantitative blood flow measurement revealed a peak systolic velocity (PSV) of $53.1 \mathrm{~cm} / \mathrm{sec}$ in the right superior thyroid artery (D). EDV, end diastolic velocity; MDV, mean diastolic velocity.

potential to monitor the therapeutic response in patients with GD $[68,73,81,84,87]$. In addition, patients who responded to treatment with drugs or radioiodine presented a significant reduction in parenchymal vascularity and the PSV of the inferior thyroidal artery, while patients who did not receive treatment or had no response to treatment showed no decrease in the PSV of the inferior thyroidal artery $[73,81,87]$.

Previous studies have shown that Doppler US is useful for evaluating disease activity in HT and subacute granulomatous thyroiditis. In the early stages of disease, HT shows diffuse hypervascularization, which can be similar to the thyroid inferno described for GD, but in a less intense form and with a lower PSV in the thyroid arteries $(<40 \mathrm{~cm} / \mathrm{sec})[75,76,85,86]$. In the latter stages of $\mathrm{HT}$, thyroid vascularity can decrease because of extensive fibrosis. However, the PSV values were significantly higher in HT patients with hypothyroidism than in their euthyroid counterparts [89], and the thyroid blood flow did not correlate with the functional state of the gland in $\mathrm{HT}[73,89]$. Unlike GD or HT, subacute granulomatous thyroiditis shows decreased or scant vascularity in the acute stage and slightly increased vascularity in the recovery stage $[91,92]$.

\section{Summary, consensus, and limitations}

Doppler US is a widely used method that may have comparable diagnostic performance to thyroid scintigraphy and does not appear to have contraindications $[76,85]$. Doppler US may be helpful for the early detection of incidental asymptomatic DTD and useful for the differential diagnosis of thyrotoxicosis, especially in the differentiation of GD from HT. In addition, Doppler US can be used to evaluate disease remission, recurrence, and response to treatment in DTD. However, it is dependent on a skilled operator $[74,77,79]$. 
Doppler US should be performed using sensitive equipment by a trained operator with good reproducibility $[74,77,79]$. It is important to use the proper technique with the appropriate transducer and equipment adjustments $[74-77,79,83,86]$. To improve clarity, further studies and guidelines regarding the standard Doppler US technique and its clinical applications are needed.

\section{Interventional Procedures (Biopsy and Ablation) US-guided thyroid biopsy}

In US-guided thyroid biopsy, Doppler US can provide information for vessel mapping along the approach route of the biopsy needle and can detect vascular complications. Doppler US can provide information on blood vessels in and around the nodule during USguided biopsy (FNA or core needle biopsy). To ensure a safe biopsy and minimize vessel injury, it is necessary to use Doppler US to completely map the vessels along the approach route (from the skin to the nodule). CDUS and SDUS provide information that allows for the differentiation of arteries and veins. After complete vessel mapping, the operator decides on the safe approach route and

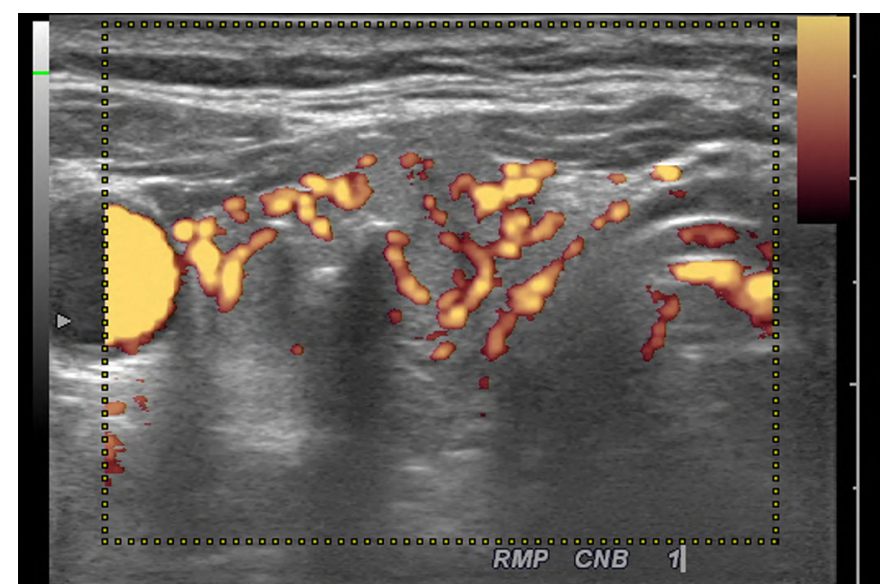

A

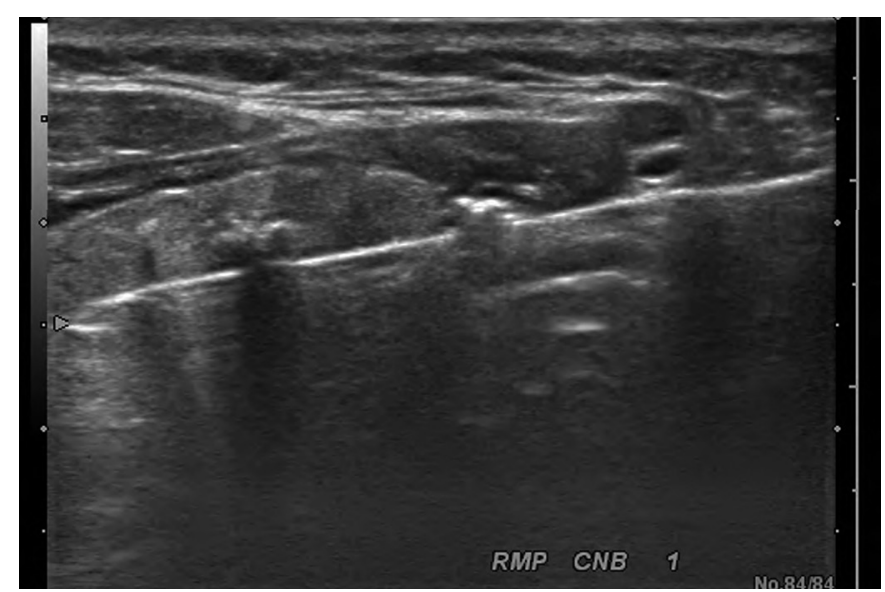

C biopsy method to avoid the biopsy needle puncturing perithyroidal vessels during the US-guided biopsy procedure [3-7,13,93] (Fig. 6). Doppler US also helps to detect vascular complications, including pseudoaneurysms, which may result from needle-induced mechanical injury to the superior or inferior thyroid artery.

\section{US-guided thyroid ablation}

In the US-guided ablation of thyroid nodules, Doppler US can be used for the following purposes: (1) pre-procedural evaluation of nodule vascularity, (2) vessel mapping along the approach route of the procedure device, and (3) post-procedural surveillance.

In a pre-procedural US examination with Doppler US, the size, proportion of solid components, vascularity, and internal contents of each nodule should be carefully evaluated according to the guidelines for radiofrequency ablation (RFA) and the consensus statement for ethanol ablation (EA) $[3,4,7]$. Doppler US provides information on the internal vascularity, feeding artery, and draining vein of each nodule (Fig. 7). Using this information, the RFA operator can decide on the appropriate treatment strategy, including the

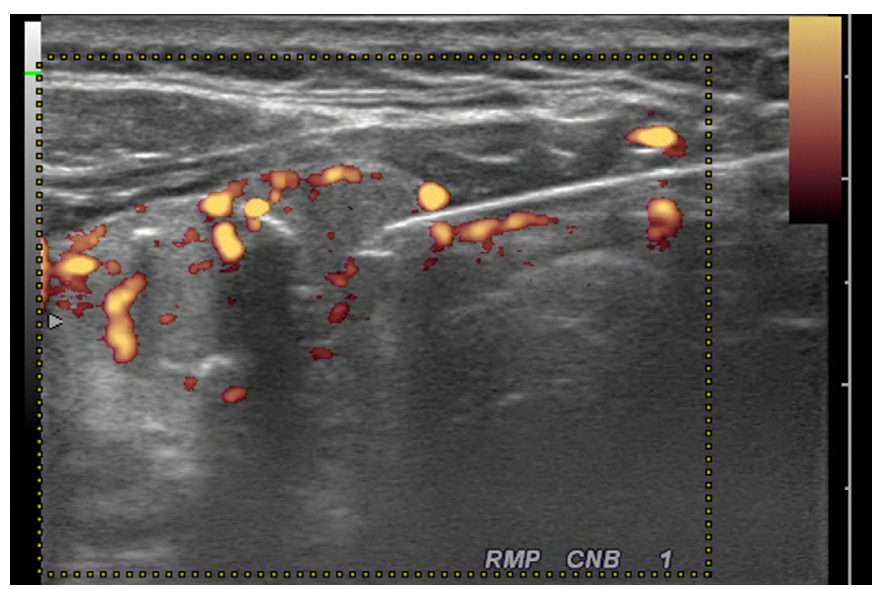

B

Fig. 6. Ultrasound (US)-guided core needle biopsy of a thyroid nodule.

A. Before the procedure, the vessels along the approach route were carefully evaluated by Doppler US. B. Using a freehand technique, a core needle was directed from the isthmus toward the nodule while avoiding the vascular structures. C. After the tip of the biopsy needle was advanced into the edge of the nodule, the stylet and cutting cannula of the needle were sequentially fired. 
ablation method, number of treatment sessions, type of electrode, and technique (including artery-first ablation and marginal venous ablation) $[4,7,94]$.

Doppler US can also provide information for vessel mapping along the approach route to avoid vessel damage $[4,7,94]$. Hematomas, caused by mechanical injury to vessels from procedural devices including the electrode or needle, can develop in perithyroidal, subcapsular, and intranodular locations. To prevent hematomas, perithyroidal vessels, including the superior and inferior thyroid arteries, should be carefully evaluated using Doppler US before

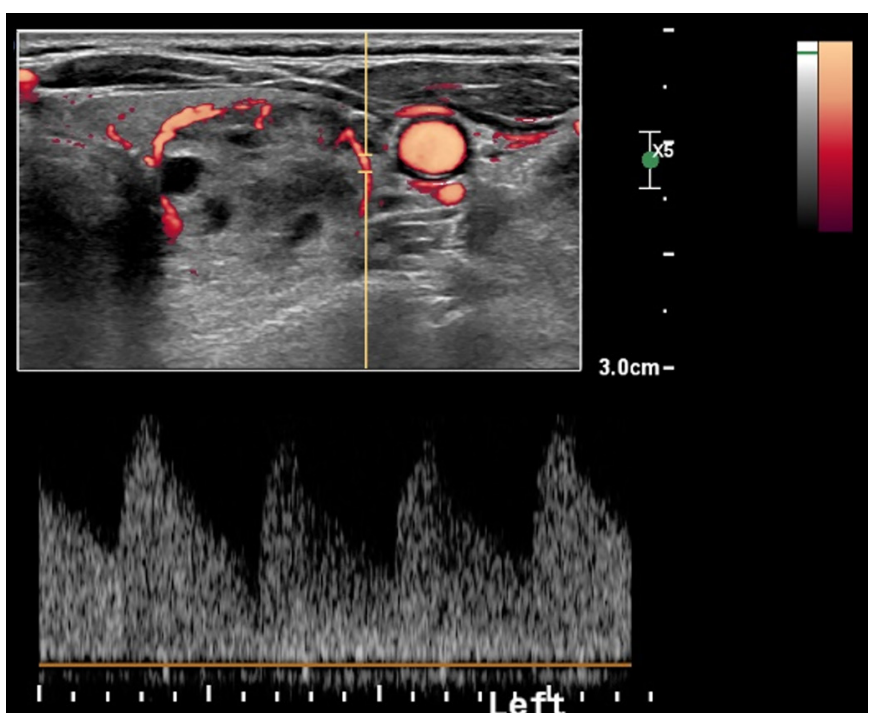

Fig. 7. Feeding artery of a thyroid nodule. Before thyroid radiofrequency ablation, the main feeding artery from the superior thyroid artery is identified on spectral Doppler ultrasonography.

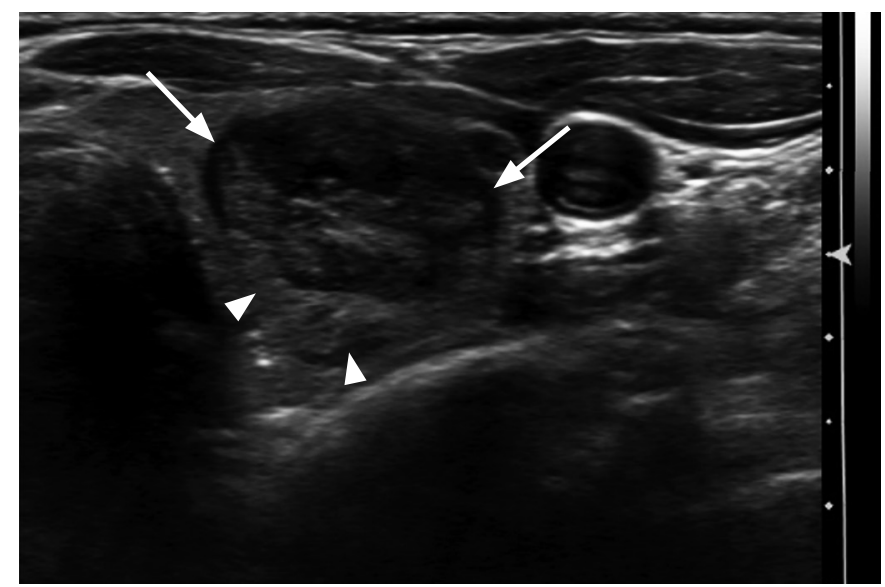

A inserting procedural devices $[4,7,94]$.

After EA and RFA procedures, Doppler US plays an important role in surveillance in addition to clinical symptoms. Doppler US is primarily used to detect any under-ablated portions of a lesion (Fig. 8). If a viable nodule portion with vascularity is detected on gray-scale US and CDUS in addition to persistent symptomatic and cosmetic problems, additional ablation is indicated $[3,4,7,95,96]$. This is because the under-ablated portion with vascularity has considerable potential for regrowth on follow-up [97]. However, CDUS does not have sufficient sensitivity to detect small vessels and slow blood flow [98]. To overcome these disadvantages of CDUS, some authors have suggested that CEUS can be used as an ancillary diagnostic tool for detecting under-ablated portions after an RFA procedure [99-101]. Doppler US is also a primary imaging modality during follow-up after other ablation procedures, including laser ablation [102-104], microwave ablation [105-107], and highintensity focused US ablation $[108,109]$. Most studies have used a color Doppler technique $[102,104-107,109]$, while some have used PDUS [108], SMI [103], or CEUS [103]. Some researchers have suggested that the ablation zone is clearer with CEUS than with CDUS $[110,111]$. Furthermore, a recent study has suggested that the accuracy of SMI for the detection of undertreated areas after laser ablation of thyroid nodules is similar to that of CEUS [103].

\section{Summary, consensus, and limitations}

In US-guided biopsy, Doppler US can provide information for vessel mapping along the approach route of the biopsy needle and can detect complications including vessel injury. For US-guided ablation, Doppler US can provide information for pre-procedural evaluation of

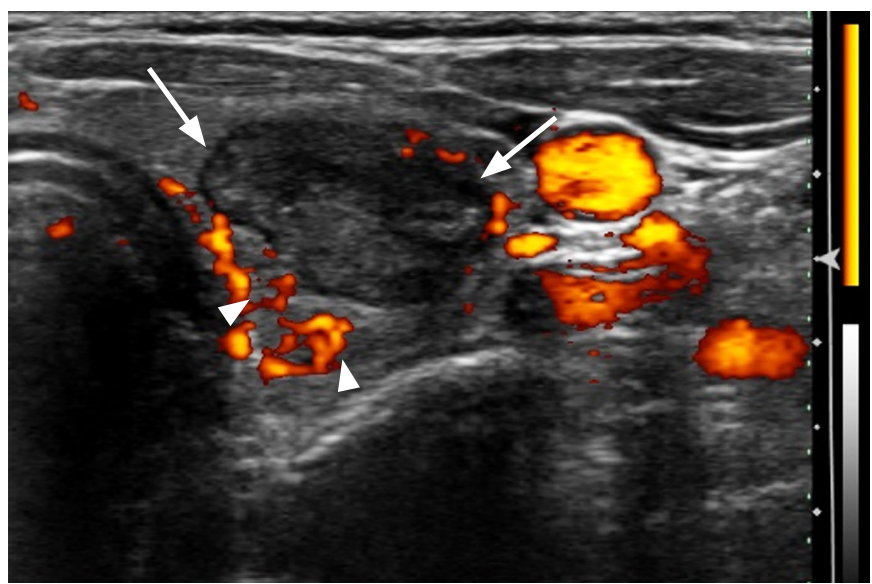

B

Fig. 8. An under-ablated nodule portion on Doppler ultrasonography.

On gray-scale (A) and Doppler ultrasonography (B), most of the nodule shows low echogenicity without vascularity (arrows), thereby suggesting an ablated portion, but the medial-posterior portion of the nodule appears isoechoic with vascularity (arrowheads), suggesting the presence of an under-ablated portion. 
nodule vascularity, vessel mapping along the approach route of the procedure device, and post-procedural surveillance.

\section{Harms and Benefits}

Doppler US is widely used to assist in the diagnosis of thyroid nodules, metastatic cervical lymph nodes in patients with thyroid cancer, and thyroiditis, as well as for the monitoring of thyroid interventions. Moreover, there is no risk of exposure to ionizing radiation. All Doppler US techniques are non-invasive, except CEUS. Therefore, the potential of CEUS-induced harm should be considered when CEUS is used.

\section{Acceptability and Applicability}

An evaluation of the domestic acceptability and applicability leads us to conclude that Doppler US is useful and reasonable for the diagnosis and monitoring of thyroid interventions. In South Korea, the Korean National Insurance Service covers the cost of US, with no additional fee for CDUS, PDUS, SDUS, or SMI. However, CEUS is less acceptable because it is an invasive technique and the cost is not covered by national insurance. In future, the optimum US method for each task should be validated.

\section{Conclusions and Future Perspectives}

The Korean Society of Thyroid Radiology presents this first consensus statement on thyroid Doppler US to improve the diagnostic performance of thyroid nodules and ensure the safety and efficacy of thyroid interventions in daily practice. Considering the increasing use of thyroid interventions in the management of thyroid lesions, operators should have a good knowledge of thyroid Doppler US. However, the high-level evidence for thyroid Doppler US is insufficient, and future studies with high evidence levels are necessary to establish future thyroid Doppler US guidelines.

ORCID: Jin Chung: https://orcid.org/0000-0001-9990-3768; Yoo Jin Lee: https:// orcid.org/0000-0003-4701-7339; Young Jun Choi: https://orcid.org/0000-00017098-5042; Eun Ju Ha: https://orcid.org/0000-0002-1234-2919; Chong Hyun Suh: https://orcid.org/0000-0002-4737-0530; Miyoung Choi: https://orcid.org/00000002-2424-9965; Jung Hwan Baek: https://orcid.org/0000-0003-0480-4754; Dong Gyu Na: https://orcid.org/0000-0001-6422-1652

\section{Author Contributions}

Conceptualization: Choi YJ, Ha EJ, Baek JH, Na DG. Data acquisition: Chung J, Lee YJ, Choi YJ, Suh CH, Choi M. Data analysis or interpretation: Chung J, Lee YJ, Choi YJ, Suh CH, Choi M. Drafting of the manuscript: Chung J, Lee YJ, Choi YJ, Ha EJ, Baek JH, Na DG. Critical revision of the manuscript: Ha EJ, Baek JH, Na DG. Approval of the final version of the manuscript: all authors.

\section{Conflict of Interest}

No potential conflict of interest relevant to this article was reported.

\section{Acknowledgments}

This work was supported and funded by the Korean Society of Radiology.

\section{References}

1. White DN. Johann Christian Doppler and his effect: a brief history. Ultrasound Med Biol 1982;8:583-591.

2. lared W, Shigueoka DC, Cristofoli JC, Andriolo R, Atallah AN, Aizen $S A$, et al. Use of color Doppler ultrasonography for the prediction of malignancy in follicular thyroid neoplasms: systematic review and meta-analysis. J Ultrasound Med 2010;29:419-425.

3. Hahn SY, Shin JH, Na DG, Ha EJ, Ahn HS, Lim HK, et al. Ethanol ablation of the thyroid nodules: 2018 consensus statement by the Korean Society of Thyroid Radiology. Korean J Radiol 2019;20:609620.

4. Kim JH, Baek JH, Lim HK, Ahn HS, Baek SM, Choi YJ, et al. 2017 Thyroid radiofrequency ablation guideline: Korean Society of Thyroid Radiology. Korean J Radiol 2018;19:632-655.

5. Lee YH, Baek JH, Jung SL, Kwak JY, Kim JH, Shin JH, et al. Ultrasoundguided fine needle aspiration of thyroid nodules: a consensus statement by the Korean Society of Thyroid Radiology. Korean J Radiol 2015;16:391-401.

6. Na DG, Baek JH, Jung SL, Kim JH, Sung JY, Kim KS, et al. Core needle biopsy of the thyroid: 2016 consensus statement and recommendations from Korean Society of Thyroid Radiology. Korean J Radiol 2017;18:217-237.

7. Na DG, Lee JH, Jung SL, Kim JH, Sung JY, Shin JH, et al. Radiofrequency ablation of benign thyroid nodules and recurrent thyroid cancers: consensus statement and recommendations. Korean J Radiol 2012;13:117-125.

8. Shin JH, Baek JH, Chung J, Ha EJ, Kim JH, Lee YH, et al. Ultrasonography diagnosis and imaging-based management of thyroid nodules: revised Korean Society of Thyroid Radiology consensus statement and recommendations. Korean J Radiol 2016;17:370-395.

9. Pearce EN, Farwell AP, Braverman LE. Thyroiditis. N Engl J Med 2003;348:2646-2655.

10. Raber W, Gessl A, Nowotny P, Vierhapper H. Thyroid ultrasound versus antithyroid peroxidase antibody determination: a cohort study of four hundred fifty-one subjects. Thyroid 2002;12:725-731. 
11. Rosario PW, Bessa B, Valadao MM, Purisch S. Natural history of mild subclinical hypothyroidism: prognostic value of ultrasound. Thyroid 2009;19:9-12.

12. Park AY, Seo BK. Up-to-date Doppler techniques for breast tumor vascularity: superb microvascular imaging and contrast-enhanced ultrasound. Ultrasonography 2018;37:98-106.

13. Rausch P, Nowels K, Jeffrey RB Jr. Ultrasonographically guided thyroid biopsy: a review with emphasis on technique. J Ultrasound Med 2001;20:79-85.

14. McDicken WN, Hoskins PR. Physics: principles, practice and artefacts. In: Pozniak M, Allan P, eds. Clinical Doppler ultrasound. 3rd ed. Edinburgh: Elsevier Ltd., 2019;1-25.

15. Rafailidis V, Huang DY, Yusuf GT, Sidhu PS. General principles and overview of vascular contrast-enhanced ultrasonography. Ultrasonography 2020;39:22-42.

16. Ha SW, Lee HJ, Cho AS, Hwang SI, Lee HJ. Evaluation of lymph node metastasis in a rabbit tumor model: correlations between contrastenhanced ultrasound and pathologic findings. Ultrasonography 2020;39:60-69.

17. Ham T, Jeon JH, Roh Y, Lee $S$, Lee $S$, Kwon H, et al. A novel method to determine hepatic segments using Sonazoid, an ultrasound contrast agent. Ultrasonography 2020;39:94-101.

18. Lee JY, Minami Y, Choi BI, Lee WJ, Chou YH, Jeong WK, et al. The AFSUMB Consensus Statements and Recommendations for the Clinical Practice of Contrast-Enhanced Ultrasound using Sonazoid. Ultrasonography 2020;39:191-220.

19. Dietrich CF, Dong Y, Kono Y, Caraiani C, Sirlin CB, Cui XW, et al. LIRADS ancillary features on contrast-enhanced ultrasonography. Ultrasonography 2020;39:221-228.

20. Yang HK, Burns PN, Jang HJ, Kono Y, Khalili K, Wilson SR, et al. Contrast-enhanced ultrasound approach to the diagnosis of focal liver lesions: the importance of washout. Ultrasonography 2019;38:289-301.

21. Bartolotta TV, Taibbi A, Midiri M, Lagalla R. Contrast-enhanced ultrasound of hepatocellular carcinoma: where do we stand? Ultrasonography 2019;38:200-214.

22. Chung YE, Kim KW. Contrast-enhanced ultrasonography: advance and current status in abdominal imaging. Ultrasonography 2015;34:3-18.

23. Darvish L, Khezri M, Teshnizi SH, Roozbeh N, Dehkordi JG, Amraee A. Color Doppler ultrasonography diagnostic value in detection of malignant nodules in cysts with pathologically proven thyroid malignancy: a systematic review and meta-analysis. Clin Transl Oncol 2019;21:1712-1729.

24. Papini E, Guglielmi R, Bianchini A, Crescenzi A, Taccogna S, Nardi F, et al. Risk of malignancy in nonpalpable thyroid nodules: predictive value of ultrasound and color-Doppler features. J Clin Endocrinol Metab 2002;87:1941-1946.

25. Deng SH, Jiang Q, Zhu YC, Zhang Y. An analysis of the clinical value of high-frequency color Doppler ultrasound in the differential diagnosis of benign and malignant thyroid nodules. Int I Clin Exp Med 2018;11:2331-2336.

26. Salehi M, Nalaini F, Izadi B, Setayeshi K, Rezaei M, Naseri SN. Grayscale vs. color doppler ultrasound in cold thyroid nodules. Glob J Health Sci 2014;7:147-152.

27. Hong YR, Wu YL, Luo ZY, Wu NB, Liu XM. Impact of nodular size on the predictive values of gray-scale, color-Doppler ultrasound, and sonoelastography for assessment of thyroid nodules. J Zhejiang Univ Sci B 2012;13:707-716.

28. Palaniappan MK, Aiyappan SK, Ranga U. Role of gray scale, color Doppler and spectral Doppler in differentiation between malignant and benign thyroid nodules. J Clin Diagn Res 2016;10:TC01-TC06.

29. Ebeed AE, Romeih MA, Refat MM, Salah NM. Role of ultrasound, color Doppler, elastography and micropure imaging in differentiation between benign and malignant thyroid nodules. Egypt J Radiol Nucl Med 2017;48:603-610.

30. Frates MC, Benson CB, Doubilet PM, Cibas ES, Marqusee E. Can color Doppler sonography aid in the prediction of malignancy of thyroid nodules? I Ultrasound Med 2003;22:127-131.

31. Chammas MC, Gerhard R, de Oliveira IR, Widman A, de Barros N, Durazzo $\mathrm{M}$, et al. Thyroid nodules: evaluation with power Doppler and duplex Doppler ultrasound. Otolaryngol Head Neck Surg 2005;132:874-882.

32. Cerbone G, Spiezia S, Colao A, Di Sarno A, Assanti AP, Lucci R, et al. Power Doppler improves the diagnostic accuracy of color Doppler ultrasonography in cold thyroid nodules: follow-up results. Horm Res 1999;52:19-24.

33. Holden A. The role of colour and duplex Doppler ultrasound in the assessment of thyroid nodules. Australas Radiol 1995;39:343-349.

34. Moon WJ, Jung SL, Lee JH, Na DG, Baek JH, Lee YH, et al. Benign and malignant thyroid nodules: US differentiation: multicenter retrospective study. Radiology 2008;247:762-770.

35. Shimamoto K, Satake H, Sawaki A, Ishigaki T, Funahashi H, Imai T. Preoperative staging of thyroid papillary carcinoma with ultrasonography. Eur J Radiol 1998;29:4-10.

36. Rago T, Vitti P, Chiovato L, Mazzeo S, De Liperi A, Miccoli P, et al. Role of conventional ultrasonography and color flow-doppler sonography in predicting malignancy in 'cold' thyroid nodules. Eur J Endocrinol 1998;138:41-46.

37. Moon HJ, Kwak JY, Kim MJ, Son EJ, Kim EK. Can vascularity at power Doppler US help predict thyroid malignancy? Radiology 2010;255:260-269.

38. Kalantari $\mathrm{S}$. The diagnostic value of color Doppler ultrasonography in predicting thyroid nodules malignancy. Int Tinnitus J 2018;22:3539.

39. Algin O, Algin E, Gokalp G, Ocakoglu G, Erdogan C, Saraydaroglu $O$, et al. Role of duplex power Doppler ultrasound in differentiation between malignant and benign thyroid nodules. Korean J Radiol 


\section{0;11:594-602.}

40. Sidhu PS, Cantisani V, Dietrich CF, Gilja OH, Saftoiu A, Bartels $E$, et al. The EFSUMB guidelines and recommendations for the clinical practice of contrast-enhanced ultrasound (CEUS) in nonhepatic applications: update 2017 (long version). Ultraschall Med 2018;39:e2-e44.

41. Bertolotto M, Catalano 0. Contrast-enhanced ultrasound: past, present, and future. Ultrasound Clin 2009;4:339-367.

42. Claudon M, Dietrich CF, Choi BI, Cosgrove DO, Kudo M, Nolsoe CP, et al. Guidelines and good clinical practice recommendations for Contrast Enhanced Ultrasound (CEUS) in the liver - update 2012: A WFUMB-EFSUMB initiative in cooperation with representatives of AFSUMB, AIUM, ASUM, FLAUS and ICUS. Ultrasound Med Biol 2013;39:187-210.

43. Ferraioli G, Meloni MF. Contrast-enhanced ultrasonography of the liver using SonoVue. Ultrasonography 2018;37:25-35.

44. Zhan J, Ding H. Application of contrast-enhanced ultrasound for evaluation of thyroid nodules. Ultrasonography 2018;37:288-297.

45. Jiang J, Shang X, Wang H, Xu YB, Gao Y, Zhou Q. Diagnostic value of contrast-enhanced ultrasound in thyroid nodules with calcification. Kaohsiung J Med Sci 2015;31:138-144.

46. Li F, Zhang J, Wang Y, Liu L. Clinical value of elasticity imaging and contrast-enhanced ultrasound in the diagnosis of papillary thyroid microcarcinoma. Oncol Lett 2015;10:1371-1377.

47. Deng J, Zhou P, Tian SM, Zhang L, Li JL, Qian Y. Comparison of diagnostic efficacy of contrast-enhanced ultrasound, acoustic radiation force impulse imaging, and their combined use in differentiating focal solid thyroid nodules. PLoS One 2014;9:e90674.

48. Ma JJ, Ding H, Xu BH, Xu C, Song LJ, Huang BJ, et al. Diagnostic performances of various gray-scale, color Doppler, and contrastenhanced ultrasonography findings in predicting malignant thyroid nodules. Thyroid 2014;24:355-363.

49. Zhang $B$, Jiang $Y X$, Liu JB, Yang M, Dai Q, Zhu QL, et al. Utility of contrast-enhanced ultrasound for evaluation of thyroid nodules. Thyroid 2010;20:51-57.

50. Wendl CM, Janke M, Jung W, Stroszczysnski C, Jung EM. Contrastenhanced ultrasound with perfusion analysis for the identification of malignant and benign tumours of the thyroid gland. Clin Hemorheol Microcirc 2015;63:113-121.

51. Chen HY, Liu WY, Zhu H, Jiang DW, Wang DH, Chen Y, et al. Diagnostic value of contrast-enhanced ultrasound in papillary thyroid microcarcinoma. Exp Ther Med 2016;11:1555-1562.

52. Nemec U, Nemec SF, Novotny C, Weber M, Czerny C, Krestan CR. Quantitative evaluation of contrast-enhanced ultrasound after intravenous administration of a microbubble contrast agent for differentiation of benign and malignant thyroid nodules: assessment of diagnostic accuracy. Eur Radiol 2012;22:1357-1365.

53. Machado P, Segal S, Lyshchik A, Forsberg F. A novel microvascular flow technique: initial results in thyroids. Ultrasound Q 2016;32:6774.

54. Cappelli C, Pirola I, Gandossi E, Marini F, Cristiano A, Casella C, et al. Ultrasound microvascular blood flow evaluation: a new tool for the management of thyroid nodule? Int J Endocrinol 2019;2019:7874890.

55. Zhu YC, Zhang Y, Deng SH, Jiang Q. A prospective study to compare superb microvascular imaging with grayscale ultrasound and color Doppler flow imaging of vascular distribution and morphology in thyroid nodules. Med Sci Monit 2018;24:9223-9231.

56. Kong J, Li JC, Wang HY, Wang YH, Zhao RN, Zhang Y, et al. Role of superb micro-vascular imaging in the preoperative evaluation of thyroid nodules: comparison with power Doppler flow imaging. J Ultrasound Med 2017;36:1329-1337.

57. Baloch ZW, Fleisher S, LiVolsi VA, Gupta PK. Diagnosis of "follicular neoplasm": a gray zone in thyroid fine-needle aspiration cytology. Diagn Cytopathol 2002;26:41-44.

58. Raber W, Kaserer K, Niederle B, Vierhapper H. Risk factors for malignancy of thyroid nodules initially identified as follicular neoplasia by fine-needle aspiration: results of a prospective study of one hundred twenty patients. Thyroid 2000;10:709-712.

59. Yang GC, Fried KO. Most thyroid cancers detected by sonography lack intranodular vascularity on color Doppler imaging: review of the literature and sonographic-pathologic correlations for 698 thyroid neoplasms. J Ultrasound Med 2017;36:89-94.

60. Fukunari N, Nagahama M, Sugino K, Mimura T, Ito K, Ito K. Clinical evaluation of color Doppler imaging for the differential diagnosis of thyroid follicular lesions. World J Surg 2004;28:1261-1265.

61. Miyakawa M, Onoda N, Etoh M, Fukuda I, Takano K, Okamoto T, et al. Diagnosis of thyroid follicular carcinoma by the vascular pattern and velocimetric parameters using high resolution pulsed and power Doppler ultrasonography. Endocr J 2005;52:207-212.

62. Yoo RE, Kim JH, Bae JM, Hwang I, Kang KM, Yun TJ, et al. Ultrasonographic indeterminate lymph nodes in preoperative thyroid cancer patients: malignancy risk and ultrasonographic findings predictive of malignancy. Korean J Radiol 2020;21:598-604.

63. Leboulleux S, Girard E, Rose M, Travagli JP, Sabbah N, Caillou B, et al. Ultrasound criteria of malignancy for cervical lymph nodes in patients followed up for differentiated thyroid cancer. J Clin Endocrinol Metab 2007:92:3590-3594.

64. Xiang $D$, Hong $Y$, Zhang B, Huang $P$, Li G, Wang $P$, et al. Contrastenhanced ultrasound (CEUS) facilitated US in detecting lateral neck lymph node metastasis of thyroid cancer patients: diagnosis value and enhancement patterns of malignant lymph nodes. Eur Radiol 2014;24:2513-2519.

65. Ahuja AT, Ying M, Yuen HY, Metreweli C. Power Doppler sonography of metastatic nodes from papillary carcinoma of the thyroid. Clin Radiol 2001;56:284-288.

66. Khati N, Adamson T, Johnson KS, Hill MC. Ultrasound of the thyroid 
and parathyroid glands. Ultrasound Q 2003;19:162-176.

67. Lane MJ, Desser TS, Weigel RJ, Jeffrey RB Jr. Use of color and power Doppler sonography to identify feeding arteries associated with parathyroid adenomas. AJR Am J Roentgenol 1998;171:819-823.

68. Ralls PW, Mayekawa DS, Lee KP, Colletti PM, Radin DR, Boswell WD, et al. Color-flow Doppler sonography in Graves disease: "thyroid inferno". AJR Am J Roentgenol 1988;150:781-784.

69. Kim DW, Eun CK, In HS, Kim MH, Jung SJ, Bae SK. Sonographic differentiation of asymptomatic diffuse thyroid disease from normal thyroid: a prospective study. AJNR Am J Neuroradiol 2010;31:19561960.

70. Pedersen OM, Aardal NP, Larssen TB, Varhaug JE, Myking O, Vik-Mo $\mathrm{H}$. The value of ultrasonography in predicting autoimmune thyroid disease. Thyroid 2000;10:251-259.

71. Yeh HC, Futterweit W, Gilbert P. Micronodulation: ultrasonographic sign of Hashimoto thyroiditis. J Ultrasound Med 1996;15:813-819.

72. Nordmeyer JP, Shafeh TA, Heckmann C. Thyroid sonography in autoimmune thyroiditis: a prospective study on 123 patients. Acta Endocrinol (Copenh) 1990;122:391-395.

73. Vitti P, Rago T, Mazzeo S, Brogioni S, Lampis M, De Liperi A, et al. Thyroid blood flow evaluation by color-flow Doppler sonography distinguishes Graves' disease from Hashimoto's thyroiditis. J Endocrinol Invest 1995;18:857-861.

74. Ota H, Amino N, Morita S, Kobayashi K, Kubota S, Fukata S, et al. Quantitative measurement of thyroid blood flow for differentiation of painless thyroiditis from Graves' disease. Clin Endocrinol (Oxf) 2007;67:41-45.

75. Erdogan MF, Anil C, Cesur M, Baskal N, Erdogan G. Color flow Doppler sonography for the etiologic diagnosis of hyperthyroidism. Thyroid 2007;17:223-228.

76. Donkol RH, Nada AM, Boughattas S. Role of color Doppler in differentiation of Graves' disease and thyroiditis in thyrotoxicosis. World J Radiol 2013;5:178-183.

77. Baek HJ, Kim DW, Lee YJ, Ahn HS, Ryu JH. Comparison of realtime and static ultrasonography diagnoses for detecting incidental diffuse thyroid disease: a multicenter study. Ultrasound Q 2019;35:233-239.

78. Kim DW. A comparative study of real-time and static ultrasonography diagnoses for the incidental detection of diffuse thyroid disease. Endocr Pract 2015;21:910-916.

79. Ahn HS, Kim DW, Lee YJ, Baek HJ, Ryu JH. Diagnostic accuracy of real-time sonography in differentiating diffuse thyroid disease from normal thyroid parenchyma: a multicenter study. AJR Am J Roentgenol 2018;211:649-654.

80. Chou YH, Chiou HJ, Tiu CM, Chiou SY, Lee CS, Tang KT, et al. Spectral pulsed Doppler blood flow measurement of normal inferior thyroid arteries. J Med Ultrasound 2001;9:119-122.

81. Caruso G, Attard M, Caronia A, Lagalla R. Color Doppler measurement of blood flow in the inferior thyroid artery in patients with autoimmune thyroid diseases. Eur J Radiol 2000;36:5-10.

82. Chiou SC, Houng HS, Li KL, Ghang TC, Lo SK, Sun RH, et al. Outcome of Graves' thyrotoxicosis after antithyroid drug treatment. Changgeng Yi Xue Za Zhi 1995;18:305-314.

83. Chen L, Zhao X, Liu H, Wang Y, Li L, Lu B, et al. Mean peak systolic velocity of the superior thyroid artery is correlated with radioactive iodine uptake in untreated thyrotoxicosis. J Int Med Res 2012;40:640-647.

84. Kurita S, Sakurai M, Kita Y, Ota T, Ando H, Kaneko S, et al. Measurement of thyroid blood flow area is useful for diagnosing the cause of thyrotoxicosis. Thyroid 2005;15:1249-1252.

85. Hari Kumar KV, Pasupuleti V, Jayaraman M, Abhyuday V, Rayudu $B R$, Modi KD. Role of thyroid Doppler in differential diagnosis of thyrotoxicosis. Endocr Pract 2009; 15:6-9.

86. Zhao X, Chen L, Li L, Wang Y, Wang Y, Zhou L, et al. Peak systolic velocity of superior thyroid artery for the differential diagnosis of thyrotoxicosis. PLoS One 2012;7:e50051.

87. Kumar KV, Vamsikrishna P, Verma A, Muthukrishnan J, Rayudu BR, Modi KD. Utility of colour Doppler sonography in patients with Graves' disease. West Indian Med J 2009;58:566-570.

88. Holm LE, Blomgren H, Lowhagen T. Cancer risks in patients with chronic lymphocytic thyroiditis. N Engl J Med 1985;312:601-604.

89. Schulz SL, Seeberger U, Hengstmann JH. Color Doppler sonography in hypothyroidism. Eur J Ultrasound 2003;16:183-189.

90. Arslan H, Unal O, Algun E, Harman M, Sakarya ME. Power Doppler sonography in the diagnosis of Graves' disease. Eur J Ultrasound 2000;11:117-122.

91. Hiromatsu Y, Ishibashi M, Miyake I, Soyejima E, Yamashita K, Koike $\mathrm{N}$, et al. Color Doppler ultrasonography in patients with subacute thyroiditis. Thyroid 1999;9:1189-1193.

92. Lee YJ, Kim DW. Sonographic characteristics and interval changes of subacute thyroiditis. J Ultrasound Med 2016;35:1653-1659.

93. Karadeniz Cakmak G, Emre AU, Tascilar O, Gultekin FA, Ozdamar SO, Comert M. Diagnostic adequacy of surgeon-performed ultrasound-guided fine needle aspiration biopsy of thyroid nodules. J Surg Oncol 2013;107:206-210.

94. Park HS, Baek JH, Park AW, Chung SR, Choi YJ, Lee JH. Thyroid radiofrequency ablation: updates on innovative devices and techniques. Korean J Radiol 2017;18:615-623.

95. Jeong WK, Baek JH, Rhim H, Kim YS, Kwak MS, Jeong HJ, et al. Radiofrequency ablation of benign thyroid nodules: safety and imaging follow-up in 236 patients. Eur Radiol 2008; 18:1244-1250.

96. Baek JH, Moon WJ, Kim YS, Lee JH, Lee D. Radiofrequency ablation for the treatment of autonomously functioning thyroid nodules. World J Surg 2009;33:1971-1977.

97. Clark T, Sabharwal T. Interventional radiology techniques in ablation. London: Springer, 2013.

98. Brunese L, Romeo A, lorio S, Napolitano G, Fucili S, Zeppa P, et al. Thyroid B-flow twinkling sign: a new feature of papillary cancer. Eur 
J Endocrinol 2008;159:447-451.

99. Che $Y$, Jin $S$, Shi $C$, Wang L, Zhang $X$, Li Y, et al. Treatment of benign thyroid nodules: comparison of surgery with radiofrequency ablation. AJNR Am J Neuroradiol 2015;36:1321-1325.

100. Tang X, Cui D, Chi J, Wang Z, Wang T, Zhai B, et al. Evaluation of the safety and efficacy of radiofrequency ablation for treating benign thyroid nodules. J Cancer 2017;8:754-760.

101. Zhao CK, Xu HX, Lu F, Sun LP, He YP, Guo LH, et al. Factors associated with initial incomplete ablation for benign thyroid nodules after radiofrequency ablation: First results of CEUS evaluation. Clin Hemorheol Microcirc 2017;65:393-405.

102. Hofling DB, Chavantes MC, Buchpiguel CA, Cerri GG, Marui S, Carneiro PC, et al. Safety and efficacy of low-level laser therapy in autoimmune thyroiditis: long-term follow-up study. Int J Endocrinol 2018;2018:8387530.

103. Liu W, Zhou P, Zhao Y, Tian S, Wu X. Superb microvascular imaging compared with contrast-enhanced ultrasound for assessing laser ablation treatment of benign thyroid nodules. Biomed Res Int 2018;2018:1025657.

104. Pacella CM, Bizzarri G, Spiezia S, Bianchini A, Guglielmi R, Crescenzi $A$, et al. Thyroid tissue: US-guided percutaneous laser thermal ablation. Radiology 2004;232:272-280.

105. Klebe J, Happel C, Grunwald F, Korkusuz H. Visualization of tissue alterations in thyroid nodules after microwave ablation: sonographic versus scintigraphic imaging. Nucl Med Commun 2015;36:260-267.

106. Teng D, Sui G, Liu C, Wang Y, Xia Y, Wang H. Long-term efficacy of ultrasound-guided low power microwave ablation for the treatment of primary papillary thyroid microcarcinoma: a 3-year follow-up study. J Cancer Res Clin Oncol 2018;144:771-779.

107. Yue W, Wang S, Yu S, Wang B. Ultrasound-guided percutaneous microwave ablation of solitary T1NOMO papillary thyroid microcarcinoma: initial experience. Int J Hyperthermia 2014;30:150-157.

108. Esnault $O$, Franc $B$, Menegaux F, Rouxel A, De Kerviler E, Bourrier $P$, et al. High-intensity focused ultrasound ablation of thyroid nodules: first human feasibility study. Thyroid 2011;21:965-973.

109. Kovatcheva RD, Vlahov JD, Stoinov JI, Zaletel K. Benign solid thyroid nodules: US-guided high-intensity focused ultrasound ablation-initial clinical outcomes. Radiology 2015;276:597-605.

110. Papini E, Bizzarri G, Bianchini A, Valle D, Misischi I, Guglielmi R, et al. Percutaneous ultrasound-guided laser ablation is effective for treating selected nodal metastases in papillary thyroid cancer. J Clin Endocrinol Metab 2013;98:E92-E97.

111. Zhou W, Zhang L, Zhan W, Jiang S, Zhu Y, Xu S. Percutaneous laser ablation for treatment of locally recurrent papillary thyroid carcinoma <15 mm. Clin Radiol 2016;71:1233-1239. 